\title{
The Acquisition of English Lexical Stress by Chinese-speaking Learners: An OT Account
}

\author{
Man Yuan ${ }^{1} \&$ Wei Cheng ${ }^{2}$ \\ ${ }^{1}$ Department of Foreign Languages, Yin Xing Hospitality Management College of CUIT, Chengdu, China \\ ${ }^{2}$ College of Foreign Studies, Jinan University, Guangzhou, China \\ Correspondence: Wei Cheng, College of Foreign Studies, Jinan University, 601 W. Huangpu Avenue, Tianhe \\ District, Guangzhou, China, 510632. Tel: 86-20-85220212. E-mail: weicheng@jnu.edu.cn
}

Received: May 6, 2017 Accepted: June 6, 2017 Online Published: June 9, 2017

doi: 10.5539/elt.v10n7p140 URL: http://doi.org/10.5539/elt.v10n7p140

\begin{abstract}
Lexical stress is an important contributor to foreign accent as well as intelligibility of second language (L2) speech. The present study intends to find out to what extent Chinese-speaking learners whose native language has less evident stress can acquire English lexical stress. A production test was administered to nine advanced Chinese learners of English and nine native English controls, who read aloud 12 types of nonce English nouns. The results showed that the Chinese participants were able to place stress correctly in two-syllable words and three-syllable words with a heavy penultimate syllable. However, irregularity was observed in three-syllable words with a light penultimate syllable, particularly $\mathrm{H}($ eavy $) \mathrm{L}(\mathrm{ow}) \mathrm{L}(\mathrm{ow})$. The results are further interpreted in Optimality Theory. It is argued that the learners' interlanguage grammar is both negatively and positively influenced by their native language. The constraint only active in Chinese causes the interlanguage to be non-nativelike. By contrast, the shared active constraints facilitate learning. Moreover, the emergence of the constraints in the interlanguage grammar which are inactive in Chinese but active in English provides evidence for the learners' ability to restructure their interlanguage phonology.
\end{abstract}

Keywords: lexical stress, Chinese EFL learners, OT, constraint reranking

\section{Introduction}

Acquiring a second language (L2) phonological system involves learning both segmental (i.e., individual sounds) and suprasegmental (i.e., syllable structure, prosody, etc.) knowledge. Failure to master either part will result in a foreign accent (Major, 2001). Particularly, suprasegmental features have been found to exert more influence on intelligibility of L2 speech than segmental features (Derwing, 2008). However, in the field of L2 phonology, much attention has been paid to segmental features. Although recent years have seen an increasing interest in L2 suprasegmental research, more is still needed to further our understanding of this issue. This paper investigates the interlanguage knowledge of English word stress of Chinese-speaking learners, whose native language is a tonal language, typologically different from English. Under the guidance of Optimality Theory (OT; Prince \& Smolensky, 1993), this study aims to find out to what extent advanced Chinese-speaking L2 learners can master English word stress patterns and intends to explain their interlanguage grammar in terms of constraint reranking.

\subsection{Previous Studies on L2 Acquisition of English Lexical Stress}

According to the different metrical systems of learners' native language, previous studies on L2 acquisition of English lexical stress can be divided into three types: languages with irregular stress (e.g., Mairs, 1989; Guion, Harada, \& Clark, 2004), languages with regular stress (e.g., Archibald, 1998; Pater, 1997), and no-stress languages (e.g., Archibald, 1997; Wong, 1991).

Spanish, like English, is a language with irregular stress. Most studies examining Spanish-speaking learners reported the effect of language transfer. For example, when asking Spanish-speaking learners to read real English words, Mairs (1989) found that some words were pronounced in the Spanish way. Guion et al. (2004) examined early and late Spanish bilinguals' production of English nonce two-syllable words and found that although early bilinguals showed similar performance to native English speakers, late bilinguals displayed more variation because they were not as sensitive to syllabic structure as native speakers. Additionally, phonologically 
similar words were observed to influence learners' placement of stress. They argued that the late bilinguals may rely more on memorization or analogy to learn English stress than on generalized English metrical patterns.

L2 learners with a regular-stress native language also exhibit difficulty with English stress. Working within the theory of Principles and Parameters, Archibald (1998) found that Polish and Hungarian-speaking learners of English showed transfer from their L1-specific parameter values in their production of real English words. Pater (1997) investigated the acquisition of English lexical stress by speakers of French, another language with regular stress. He examined the subjects' production of nonce three- and four-syllable words and found that French-speaking learners could reset the parameters. However, although some parameter values in learners' interlanguage were like English, some were not like either English or French, such as word headedness and directionality.

The last kind of studies focuses on speakers of no-stress languages such as Chinese, Japanese, Korean, Thai, etc. Wong (1991) examined Cantonese speakers' stress placement in nonce English words and found that the subjects were able to acquire certain aspects of English stress. She concluded that a lack of stress in Cantonese does not create difficulty for English L2 learners. Archibald (1997) conducted a longitudinal study on Chinese and Japanese speakers' production of real English words. He did not find an effect of syllable type and lexical category and argued that the Chinese and Japanese subjects did not compute English lexical rules but rather stored English stress lexically. Guion (2005) investigated Korean learners' knowledge of English stress and observed native language influence. She found that late Korean bilinguals were not sensitive to both syllabic type and lexical category and attributed this to transfer in that Korean has phrase-level pitch rather than lexical stress. Wayland, Guion, Landfair, and Li's (2006) study of Thai-speaking learners showed that the subjects were sensitive to English syllabic type in stress placement, but they could not determine whether this is due to acquisition or transfer, given that Thai tonal placement is also related with syllable type. In a large cross-linguistic study, Altmann (2006) investigated Chinese, Japanese and Korean learners' placement of stress in nonce English words and found them to be non-nativelike. Particularly, the Chinese subjects performed the worst and tended to place stress on the last stressable syllable. She argued that since Chinese is a no-stress language with no parameter preset for stress, it is not clear which parameter is misset by the subjects.

From previous studies, it can be seen that native language plays an important role in the acquisition of L2 English lexical stress. Learners from a no-stress native language appear to experience more difficulty than learners from a stress language. However, conflicting results were also observed, as in the results of Wong (1991) and Archibald (1997). One of the reasons for this, also a limitation of most previous studies, is that learner proficiency is not taken into consideration. For example, in Archibald's (1997) study, the two Mandarin speakers were not at the same proficiency level, and he didn't consider such difference. Another gap in previous studies is that few studies on L2 lexical stress acquisition have worked in the framework of Optimality Theory, the current mainstream model in phonology. One exception is Lee and Cho (2011). However, their study focused on derived words and the relationship between perception and production. In view of such gaps in L2 stress research, this paper examines advanced Chinese speakers' interlanguage knowledge of English lexical stress from an OT perspective.

\subsection{English and Chinese Metrical Phonology}

English is a stress language. In multiple-syllable words, a certain syllable is produced more prominently than others. However, English stress patterns are not as predictable as fixed-stress languages such as French. Yet, certain patterns can also be observed. Generally, there is a difference between nouns and verbs in terms of lexical stress. For nouns, if the penultimate syllable is heavy, it is stressed; otherwise the antepenultimate syllable is stressed (McMahon, 2002). A heavy syllable is defined as one with a branching rhyme, that is, with a tense vowel (long or diphthong) or a vowel plus coda.

From the perspective of metrical phonology (Hayes, 1995), syllables form feet, which in turn group into a prosodic word. A foot can be binary or unbounded and is headed by a strong element. If a language is quantity-sensitive, a heavy syllable will form an individual foot. The foot that becomes dominant in the prosodic word is the unit that bears stress. English shows a left-dominant binary foot constructed from the right-edge. In nouns, the last syllable is extrametrical, that is, not subject to metrical rules. The main stress falls on the right edge of the prosodic word. Since English is a quantity-sensitive language, syllable weight plays a crucial role in English stress placement.

Chinese, on the other hand, is known to be a no-stress language, the assumption commonly held by previous studies on Chinese learners' acquisition of English stress. It is argued that without stress in their native language Chinese learners cannot reset the parameters (Altmann, 2006; Archibald, 1997). However, as pointed out by 
Duanmu (2007), Chinese also has stress. The reason why stress in Chinese is not as easy to perceive as in English is that Chinese has lexical tones and that most Chinese words are monosyllabic. He argued that in dissyllabic words or compounds, the most common syllable pattern $(70 \%$ of Chinese disyllabic words) is heavy-heavy, i.e., $\mathrm{H}(\mathrm{HØ)}$, with the second syllable louder in intensity and longer in duration. For these words, the final syllable forms a separate syllabic foot (left-headed) with an empty beat, and binary feet are formed for other syllables from the left. If this is the case, then Chinese speakers also have the knowledge of stress in their native grammar. It is just that they don't "use" such knowledge as often as English speakers because Chinese does not have many poly-syllabic words. This paper adopts this view of Chinese stress.

\subsection{Optimality Theory}

OT, advocated by Alan Prince and Paul Smolensky in 1993, is a development of Generative Grammar. OT holds that there is a set of possible pronunciations produced by GEN (generator) for any particular form which is called the 'input'. The possible pronunciations are known as 'candidates'. These candidates are evaluated by a set of ranked constraints, and the candidate that best satisfies the ranking is the optimal output. There are two main categories of constraint. One is defined as Faithfulness Constraint which aims to keep identity between input and output, and the other is Markedness Constraint whose function is to make the output well-formed. In a word, in the framework of OT, the output is a legal candidate winning out of a set of possible candidates produced by Generator after the working of Evaluator, which is in effect a set of hierarchical constraints ranked according to their priority in a language.

Different from the traditional generative grammar in which UG is defined as a set of rules which cannot be violated, OT regards UG as a set of universal constraints which are however violable. The asymmetry between languages is due to the different ranking of these universal constraints. The following metrical constraints are at crucial play in English and Chinese metrical phonology.

(1) Metrical constraints

a. FT-BIN: Feet are binary under moraic or syllabic analysis.

b. RHTYPE=T: Feet have initial prominence.

c. ALL-FT-RIGHT: Every foot stands at the right edge of the PrWd.

d. NON-FINALITY: No foot is final in PrWd.

e. RIGHTMOST: The head foot is rightmost in PrWd.

f. ALL-FT-LEFT: Every foot stands at the left edge of the PrWd.

All of the constraints in (1) are markedness constraints taken from Kager (1999). The first five constraints (a-e) are crucial in English stress system. FT-BIN and RHTYPE $=$ T determine that English has left-headed binary foot, i.e. trochee. ALL-FT-RIGHT regulates that foot is constructed from right. NON-FINALITY recognizes extrametricality at the right edge in English. RIGHTMOST places primary stress on the rightmost foot.

As for Chinese metrical phonology, four of the constrains in (1) are crucial. Since Chinese has a trochee, constraints FT-BIN and RHTYPE $=\mathrm{T}$ are active in Chinese. As introduced above, most Chinese di- and poly-syllabic words have final stress. Thus, RIGHTMOST is also at play. The last one is exclusively important in Chinese metrical phonology, as Chinese metrical foot is constructed from the left (Duanmu, 2007; Ma, 2008).

To sum up, as far as the five constraints are concerned, the difference between English and Chinese is that ALL-FT-RIGHT and NON-FINALITY are ranked lower in Chinese, and that ALL-FT-LEFT is not active in English. Therefore, to acquire English lexical stress, Chinese-speaking learners need to re-rank these constraints, specially, promote FT-RIGHT and NON-FINALITY and demote ALL-FT-LEFT. In this paper, we investigated advanced Chinese learners' acquisition of English lexical stress by looking at their placement of stress on twoand three-syllable nonce nouns in a production experiment, which enabled us to find out to what extent their interlanguage has these constraints reranked. Below, we report the experiment.

\section{Method}

\subsection{Participants}

Nine native Chinese speakers (one male and eight females) volunteered to take part in the study. All were graduate students at a research University in the U.S. and received a BA in English in China. They had learned English for an average of 12.5 years (Range: 10-17) and had lived in the U.S. for an average of 28 months (Range: 4-60). No proficiency test was conducted, but all of them rated themselves as advanced $(N=8)$ or near-native $(N=1)$ speakers of English. Six of them had taken the Internet-based TOEFL, and the average score 
for Speaking was 25/30 (Range: 23-26). One took IELTS and got 6/9 on the speaking part. The other two participants had not taken any speaking test at the time of the experiment, but both of them had been in the U.S. for more than four years. Following Guion et al. (2004) and Wayland et al. (2006), a test was conducted to probe their ability to produce stress in real English words. The test items were taken from Guion et al., among which 18 words had regular stress patterns and 18 words irregular patterns (see Appendix A for stimuli). The participants were asked to read aloud the words printed on a word list. The results of the test are presented in Table 1. It can be seen that they received a high score in the task, indicating their successful mastery of stress in known English words. Given the results of their TOEFL/IELTS scores and performance in the real-English-word-stress measurement, as well as the fact that they majored in English in their undergraduate studies, they could be roughly considered to have high proficiency of English in terms of speaking, particularly concerning lexical stress. In addition, nine native English speakers were recruited as controls. All were undergraduate students at the same university and received course credit for participation.

Table 1. Mean percentage of correct stress production in real English words by L2 participants

\begin{tabular}{lll}
\hline Total & Words with regular stress pattern & Words with irregular stress pattern \\
\hline $94.1 \%$ & $92.6 \%$ & $95.7 \%$ \\
\hline
\end{tabular}

\subsection{Materials}

A production test was administered to both native and nonnative English participants. The test material was a list of nonce words mainly basely on Altmann (2006). The reason why real words were not used is that it is possible that learners actually memorize the stress of the words rather than apply the phonological rules. Two- and three-syllable words were tested. The words were created on the basis of the combination of different syllable weight (heavy and light). Therefore, a total of 12 syllable types (4 two-syllable and 8 three-syllable) were formed Each syllable type had 10 items, making a total of 120 stimuli. All the nonce words were designed in accordance with English phonological rules. Guion et al. (2004) found that stress placement on nonce words may be influenced by phonologically similar words. Thus, the nonce words in the present study were created to be as dissimilar from real English words as possible. Before the experiment, a native English speaker with expertise in phonetics reviewed the material to make sure that the stimuli comply with the English phonological system. After that, a pilot study was conducted on seven native English speakers. The words that were frequently not pronounced in the intended way were modified. The final words were randomly printed on four pieces of paper, 30 on each sheet. (See Appendix B for a full list of stimuli.)

Difference lexical categories have different stress patterns. Therefore, the nonce words were all intended as nouns. To make sure that they pronounced the words as nouns, the participants were told that all the words were the names of the latest American products produced in the US.

\subsection{Procedure and Coding}

The experiment was conducted in a quiet room on an individual basis. The participants were asked to read aloud the nonce words at a normal speed. They were allowed to correct their pronunciation if they were not satisfied with their initial try. If this was the case, only the corrected one was coded. If there was a pause in their pronunciation of a single word, they were asked to pronounce the word again. Their pronunciation was recorded by a digital recorder (Sony PCM-M10/R). Before the experiment, the participants filled in a language background questionnaire and performed ten practice trials which were not included in the test.

Afterwards, one of the authors listened to the recordings and coded the tokens. Since English spelling is not always consistent with the pronunciation, some words were not pronounced in the intended way. These trials were classified into the syllable type that they were realized as. In addition, some words were not pronounced clearly, making it difficult to determine their stress. Such words were not coded.

\section{Results}

The percentage of correct stress placement in each syllable type as expected by the metrical rules was calculated for each participant. An independent t-test was conducted to compare the means between the Chinese and the American groups.

Figure 1 shows the comparison for two-syllable words. As the figure displays, the Chinese participants performed almost the same as the native speakers. Independent t-tests demonstrated that there was no significant 
difference between the two groups in each syllable type (all p's> .05). Thus, the results indicate that the Chinese participants mastered the stress patterns of two-syllable words. They correctly placed stress on the first syllable, even though the second one is heavy as in HH and LH. The finding is different from Altmann's (2006) study. She only looked at $\mathrm{HH}$ and the Chinese subjects tended to place stress on the last heavy syllable (71.1\%). However, it should be noted that the last heavy syllable was represented as a long vowel in her study, but as a vowel plus coda in the present study. This may be one of the reasons for the difference.

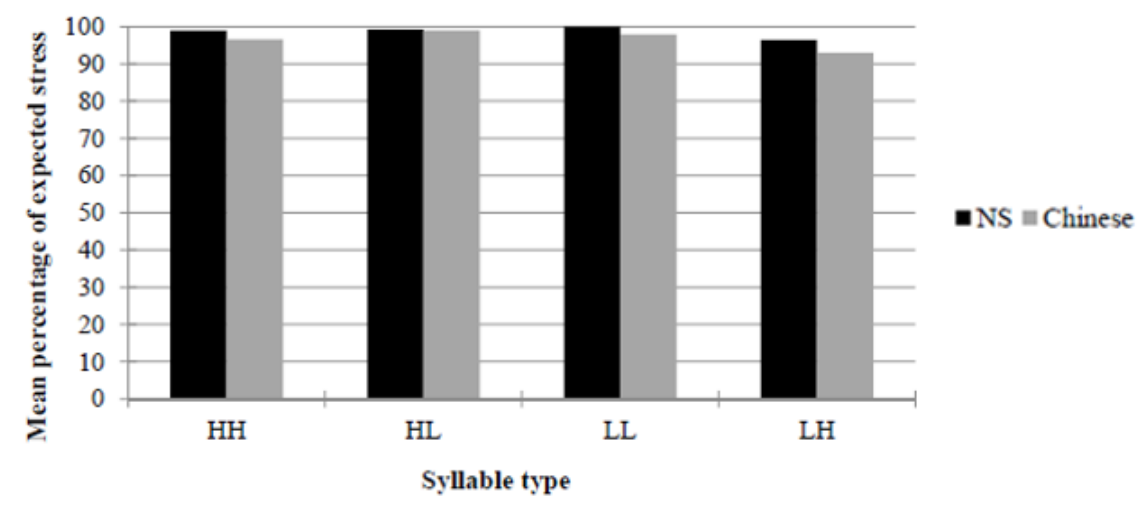

Figure 1. Mean percentages of production with expected stress in two-syllable words

As introduced in the introduction, primary stress placement in three-syllable words hinges on the weight of the second syllable. If it is heavy, then it receives stress; if it is light, then the antepenultimate syllable is stressed. The results for three-syllable words are presented according to the syllable weight of the penultimate syllable in Figure 2 and 3, respectively.

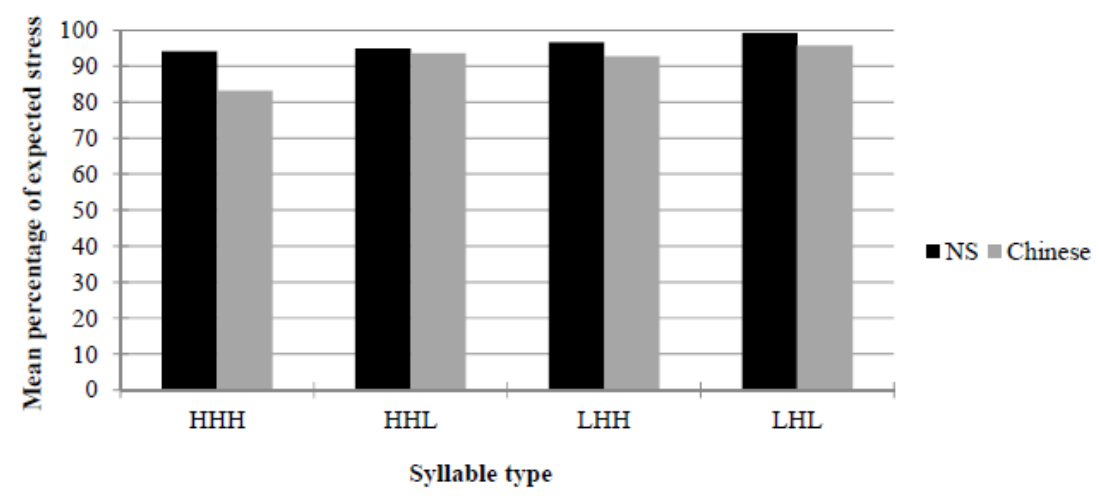

Figure 2. Mean percentages of production with expected stress in three-syllable words with a heavy penultimate syllable

As can be seen in Figure 2, when the penultimate syllable was heavy, the Chinese participants stressed the word penultimately in most cases as expected by the rule. Their performance was also very similar to the native speakers except for the type of $\mathrm{HHH}$, where there was an $11 \%$ difference. However, independent t-tests show that there was no significant difference between the two groups in each of the four syllable types with heavy penultimate syllable (all $p$ 's $>.05$ ). Therefore, the Chinese subjects appeared to have mastered stress assignment in these types of nouns.

Figure 3 exhibits a different picture. When the second syllable was light, both the Chinese and native English participants performed worse than in other syllable types. The most common error was to place stress on the second syllable with a lax vowel. For instance, the LLL word selega was pronounced as [sə'legə] instead of ['seləgə]. Tokens in these four types were fewer than in other types. The reason is that many participants tended 
to stress the second syllable, making it a long vowel. For example, meffala was often pronounced as [mə'fa:lə] rather than ['mefələ] as intended.

Although the native subjects scored less than the Chinese subjects in the syllable type of LLL (39.2\% vs. 59.1\%), no significant difference between the two groups in this syllable type ( $p>.05)$. Besides, no significant difference was observed in HLH $(p>.05)$. Significant difference was found between the two groups in the other two types, namely, LLH and HLL (both $p<.05$ ). Particularly, in HLL, the difference was nearly $40 \%$.

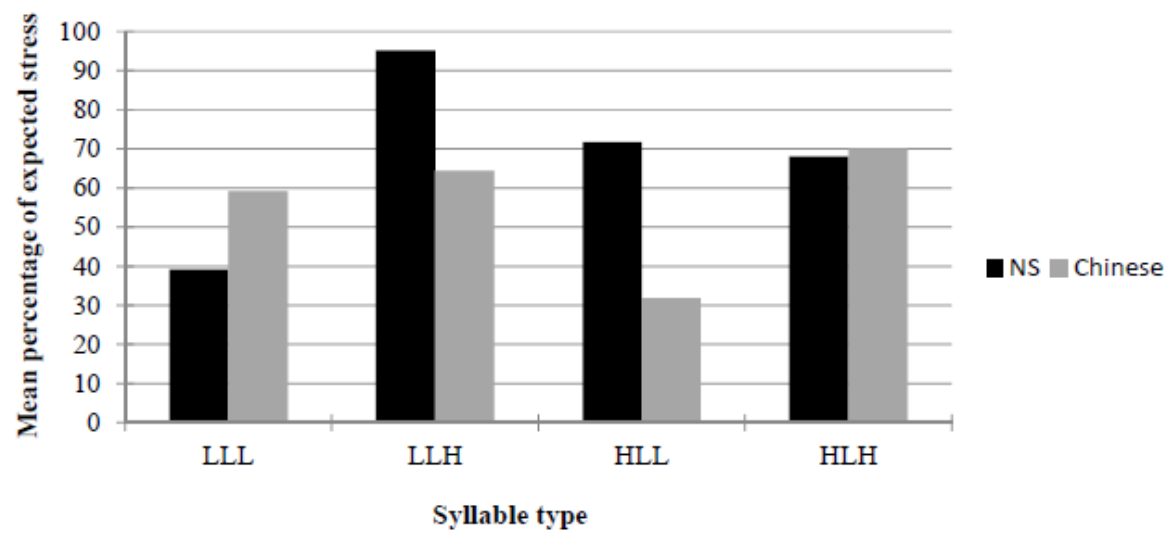

Figure 3. Mean percentages of production with expected stress in three-syllable words with a light penultimate syllable

\section{Discussion}

As mentioned in the previous section, the results contradict Altmann (2006)'s finding that Chinese learners tend to stress the last heavy syllable. This is partly because of the design of nonce words. In her study, all heavy syllables ended with a long vowel. In the present study, the final heavy syllable contained vowel plus coda. Therefore, it is possible that long vowels are more likely to attract stress for Chinese learners. This can be investigated in future study.

In addition, the study also yields different findings from Archibald (1997). The Chinese subjects in his study were claimed to exhibit no clear patterns of acquisition. However, the current study shows that the Chinese participants were quite consistent and native-like in most syllable types. Therefore, Chinese learners do not simply memorize lexical stress on a word-by-word basis as claimed by Archibald, but rather generalize abstract stress patterns.

The study largely echoes Wong's (1991) findings on Cantonese speakers. In her study, the Cantonese participants performed regularly in both two- and three-syllable nouns. In the present study, it is also found that two-syllable nouns and most three-syllable nouns generally do not pose difficulty for the Chinese subjects. However, different from Wong, variance was observed in three-syllable words with light penultimate syllable. Such variation may be due to the difference in research design. For example, in her study, each type of word only had four items. If more items were used, the results might be different.

Moreover, consistent with previous findings, no apparent effect of native-language transfer was observed. Previous studies attribute this to the no-stress property of Chinese. That is, there is nothing to be transferred from a language which lacks stress. However, as introduced at the beginning, Chinese may have final stress in most disyllabic words or compounds (Duanmu, 2007). Yet, as the current study shows, in two-syllable words, like native English speakers the Chinese subjects placed stress on the first syllable, indicating that advanced Chinese learners can overcome native language influence in their acquisition of lexica stress for two-syllable words.

Although the participants in the study showed native-like performance in most syllable types, their interlanguage grammar was still not target-like in that they got very low score in the syllable type of HLL. From the perspective of Optimality Theory, it can be interpreted that the relevant constraints are in a restructuring process, in which the ranking is neither native-like nor target-like. Specifically, we argue that in their current interlanguage grammar, the metrical constraints are ranked in the following way. 
(2) Ranking schema in L2 participants' interlanguage grammar concerning English lexical stree

\section{FT-BIN, RHTYPE $=$ T $>>$ ALL-FT-RIGHT, ALL-FT-LEFT $>>$ NON-FINALITY $>>$ RIGHTMOST}

The reason ALL-FT-RIGHT and ALL-FT-LEFT are unranked with others is that the Chinese learners tended to place stress on the middle syllable. Therefore, it is likely that ALL-FT-LEFT, the constraint active in the learners' native grammar is still at play in the interlanguage, but meanwhile in interaction with the promoted ALL-FT-RIGHT. The Chinese subjects exhibited sensitivity to extrametricality in that the final syllable was generally not stressed. Therefore, NON-FINALITY, the constraint ranked lower in the native grammar, has also moved up to a crucial position. However, unlike in the target language grammar where it is ranked higher than ALL-FT-RIGHT, it is positioned below it in the interlanguage grammar upon the observation that in HLL, the second syllable was stressed by most Chinese participants. The second syllable can bear stress only when the last two light syllables can form a foot.

Below, we illustrate how the constraints as ranked above account for the data. In the first place, consider HLL, the syllable type in which the Chinese learners scored significantly lower than the native speakers.

(3) HLL

\begin{tabular}{|l|l|l|l:l|l|l|}
\hline tay.se.la & FT-BIN & RHTYPE=T & ALL-FT-RIGHT & ALL-FT-LEFT & NON-FINALITY & RightMOST \\
\hline a. (tay).(sé.la) & & & $* * !$ & $*$ & $*$ & \\
\hline b. (táy).se.la & & & $* * !$ & & & $* *$ \\
\hline c. ${ }^{-}$tay.(sé.la) & & & & $*$ & $*$ & \\
\hline d. (táy.se.la) & $* !$ & & & $*$ & $*$ & \\
\hline
\end{tabular}

In (3), even though Candidate c tay.(sé.la) has two violations, it still wins out in that both violations are not fatal. Its most competitive rival Candidate $b$ is out because of the asymmetry of the number of syllables separating the foot from the edge. Therefore, ranking NON-FinALITY below ALL-FT-RighT and ALL-FT-LEFT makes sure that the optimal output will not be ruled out simply because the last syllable is not made extrametrical.

Now let us look at LLL, which only has light syllables.

(4) LLL

\begin{tabular}{|c|c|c|c|c|c|c|}
\hline je.te.ka & FT-BIN & RHTYPE $=\mathrm{T}$ & ALL-FT-RIGHT & ALL-FT-LEFT & NON-FINALITY & RIGHTMOST \\
\hline a. je.(té.ka) & & & & $*$ & $* !$ & \\
\hline b. (jé.te).ka & & & $*$ & & & $*$ \\
\hline c. (jé.te.ka) & $* !$ & & & & $*$ & \\
\hline
\end{tabular}

In (4), Candidate b (jé.te).ka is selected because the last syllable is made extrametrical. By contrast, Candidate a is out because the final syllable is not extrametrical. From this example, it can be seen that constraint NON-FINALITY is crucial in the Chinese learners' interlanguage grammar. In addition, it displays that ALL-FT-RIGHT and ALL-FT-LEFT should be equal in rank. If ALL-FT-RIGHT were ranked higher, then Candidate $b$ would be ruled out. ALL-FT-LeFT cannot be ranked higher either, otherwise Candidate $c$ in (4) would not be selected.

The following is an illustration of three-syllable words with heavy penultimate syllable.

(5) $\mathrm{HHH}$

\begin{tabular}{|l|l|l|l|l|l|l|}
\hline pow.dee.tan & FT-BIN & RHTYPE=T & ALL-FT-RIGH & ALL-FT-LEFT & NON-FINALITY & RIGHTMOST \\
\hline a. (pow).(dee).(tán) & & & $*, * * !$ & $* * *$ & $*$ & \\
\hline b. (pów).dee.tan & & & $* *$ & & & $* * !$ \\
\hline c. ${ }^{-}$pow.(dée).tan & & & $*$ & $*$ & & $*$ \\
\hline d. pow.dee.(tán) & & & & $* *$ & $* !$ & \\
\hline e. (pów.dee.tan) & $* !$ & & & & $*$ & \\
\hline
\end{tabular}


As (5) shows, both Candidate $\mathrm{b}$ and $\mathrm{c}$ had the same number of violations in the first five constraints. Candidate $\mathrm{c}$ finally wins out because the stress-bearing foot is closer to the right-edge. This comparison proves the importance of the constraint RIGHTMOST.

From the interactions of these constraints, we can find that the learners' current grammar is not completely unaffected by their native language. As mentioned above, ALL-FT-LEFT is an active constraint in Chinese metrical system. Its active operation in the interlanguage grammar indicates a negative influence of native language. Since this constraint determines a left-to-right foot construction, it also implies that the direction of foot construction in English is likely to be difficult to acquire for Chinese speakers. Future studies can explore the reasons for this. In addition, native language may be facilitative in Chinese learners' acquisition of English lexical stress. As mentioned in the introduction, certain constraints are active in both languages, such as FT-BIN, RHTYPE $=$ T, and RightMOST. Therefore, when learning English lexical stress, Chinese learners may experience less difficulty in figuring out their role in the target grammar and hence easily position them in the interlanguage.

Apart from native language influence, there is clear evidence of acquisition as reflected in the promotion of the two constraints ALL-FT-RIGHT and NON-FINALITY, which are ranked low in the native Chinese grammar. This indicates that L2 learners have the ability to re-rank the constraints of metrical phonology on the basis of the input they are exposed to, as found in Broselow, Chen and Wang (1998).

\section{Conclusion}

This study examined advanced Chinese learners' acquisition of English lexical stress by looking at their placement of stress on two- and three-syllable nonce nouns. The results show that Chinese participants were sensitive to syllable weight and native-like in most syllable types. However, there is also some variance from native speakers, especially in three-syllable words with light penultimate syllable. Particularly, L2 participants scored significantly low in the syllable type of HLL. Their performance is explained by referring to six crucial OT constraints, three active in both Chinese and English, two active in English, and one active in Chinese. The learners' interlanguage grammar is both negatively and positively influence by their native language. The constraint only active in Chinese causes the interlanguage to be non-nativelike. By contrast, the shared constraints facilitate learning. Moreover, the emergence of the constraints which are inactive in Chinese but active in English provides evidence for L2 learners' ability to restructure their interlanguage.

The study has several limitations. First, the sample size is small. Future studies may increase the sample size. Second, we only focused on advanced learners. In future research, learners' English proficiency may be taken into consideration to probe the development of their acquisition of lexical stress in different stages.

\section{Acknowledgments}

This paper was partially supported by the New Faculty Start-up Grant of Jinan University (88017434) awarded to Wei Cheng.

\section{References}

Altmann, H. (2006). The perception and production of lexical stress: A cross-linguistic experimental study (Unpublished PhD dissertation). University of Delaware, Newark, DE.

Archibald, J. (1997). The acquisition of English stress by speakers of nonaccentual languages: Lexical storage versus computation of stress. Linguistics, 35, 167-181. https://doi.org/10.1515/ling.1997.35.1.167

Archibald, J. (1998). Second language phonology. Amsterdam: John Benjamins. https://doi.org/10.1075/lald.17

Broselow, E., Chen, S.-I., \& Wang, C. (1998). The emergence of the unmarked in second language phonology. Studies in Second Language Acquisition, 20, 261-280. https://doi.org/10.1017/s0272263198002071

Derwing, T. M. (2008). Curriculum issues in teaching pronunciation to second language learners. In J. G. Hansen-Edward, \& M. L. Zampini (Eds.), Phonology and second language acquisition (pp. 347-369). Amsterdam: John Benjamins. https://doi.org/10.1075/sibil.36.17der

Duanmu S. (2007). The phonology of standard Chinese. New York: Oxford University Press.

Guion, S.G. (2005). Knowledge of English word stress patterns in early and late Korean-English bilinguals. Studies in Second Language Acquisition, 27, 503-533. https://doi.org/10.1017/s0272263105050230

Guion, S. G., Harada, T., \& Clark, J. J. (2004). Early and late Spanish-English bilinguals' acquisition of English word stress patterns. Bilingualism: Language and Cognition, 7, 207-226. https://doi.org/10.1017/S1366728904001592

Hayes, B. (1995). Metrical stress theory: Principles and case studies. Chicago: The University of Chicago Press. 
Kager. R. (1999). Optimality Theory. Cambridge, UK: Cambridge University Press. https://doi.org/10.1017/CBO9780511812408

Lee, S., \& Cho, M. H. (2011). An OT account of the precedence relationship between perception and production in the acquisition of English stress. Pozań Studies in Contemporary Linguistics, 47, 54-80. https://doi.org/10.2478/psicl-2011-0006

Ma, Q. W. (1998). You xuan lun [Optimality theory]. Shanghai, China: Shanghai Educational Publishing House.

Mairs, J. L. (1989). Stress assignment in interlanguage phonology: An analysis of the stress system of Spanish speakers learning English. In S. M. Gass, \& J. Schachter (Eds.), Linguistic perspectives on second language acquisition (pp. 260-283). Cambridge: Cambridge University Press. https://doi.org/10.1017/CBO9781139524544.019

Major, J. (2001). Foreign accent: The ontogeny and phylogeny of second language phonology. Mahwah, NJ: Lawrence Erlbaum Publishers.

MaMahon, A. (2002). An introduction to English phonology. Edinburgh, UK: Edinburgh University Press.

Pater, J. P. (1997). Metrical parameter missetting in second language acquisition. In S. J. Hannahs, \& M. Young-Scholten (Eds.), Focus on phonological acquisition (pp. 235-261). Amsterdam: John Benjamins.

Prince, A., \& Smolensky, P. (1993). Optimality Theory: Constraint interaction in generative grammar (Unpublished manuscript). Rutgers University, New Brunswick, NJ.

Wayland, R., Guion, S. G., Landfair, D., \& Li, B. (2006). Native Thai speakers' acquisition of English lexical stress patterns. Journal of Psycholinguistic Research, 35, 285-304. https://doi.org/10.1007/s10936-006-9016-9

Wong, C. S. P. (1991). The stress patterns of nonsense English words of Cantonese-speaking ESL learners. CUHK Papers in Linguistics, 3, 83-111.

\section{Appendix A}

\section{The English Words Used in the Pre-Experiment Stress Test (from Guion et al., 2004)}

Consistent with stress rules:

Agent, Aspect, Machine, Prestige, Basket, Manage, Habit, Percent, Potato, Agenda, Origin, Numeral, Hurricane, Behave, Magazine, Maintain, Cancel, Indicate, Compensate.

Inconsistent with stress rules:

Descent, Pillow, Window, Hotel, Giraffe, Medium, Calendar, Eleven, Banana, Spaghetti, Kangaroo, Borrow, Rotate, Begin, Possess, Introduce, Entertain. 


\section{Appendix B}

\section{Test Stimuli of the Experiment}

Two-syllable words:

\begin{tabular}{|l|l|l|l|}
\hline HH & HL & LL & LH \\
\hline howtan & noova & ledda & vessen \\
\hline vaymen & loyfa & fedda & fessen \\
\hline nooden & nyeda & vippa & fennen \\
\hline loigan & rouna & liffa & dellan \\
\hline joutan & deysa & levva & kutten \\
\hline deenan & cheela & fivva & buttin \\
\hline neeson & toefa & kella & satten \\
\hline kooren & tayla & mella & gutton \\
\hline moyron & deema & rikka & pessen \\
\hline zaylen & soora & neffa & teppan \\
\hline
\end{tabular}

Three-syllable words:

\begin{tabular}{|l|l|l|l|l|l|l|l|}
\hline HLL & HLH & HHL & HHH & LHH & LHL & LLH & LLL \\
\hline taysena & keavalin & hoefayla & powdeetan & lafeaven & dafeema & Gakalin & jeteka \\
\hline leetema & naysamen & moyrouna & yeeloiken & nipowben & menoysa & Dellaven & mettela \\
\hline koyseda & koolaven & touneema & foilougen & daboesen & pecoika & Lapeton & selema \\
\hline koydela & rouleten & layteesa & dowkooven & nimoytin & deboova & Settadin & gidema \\
\hline seebela & soodelen & voozayla & cheelayman & maleybin & taroyma & Kedegen & selega \\
\hline saymela & meeganen & foyrouba & veasoolen & lahoefen & zedoola & Mellafen & tugela \\
\hline soopera & boevelin & leysouda & beazaylen & tesoiden & laveega & Lesitin & lebena \\
\hline faydela & booleden & keedeysa & teezowkan & bafoeren & nazeyda & Sulletee & jeleda \\
\hline cowtela & houleden & leytawma & royseemen & pecoitan & safouna & Tedenee & ketela \\
\hline feeveda & feetacon & jeedoova & moysealon & dafeenon & bufoola & Livviden & meffala \\
\hline
\end{tabular}

\section{Copyrights}

Copyright for this article is retained by the author(s), with first publication rights granted to the journal.

This is an open-access article distributed under the terms and conditions of the Creative Commons Attribution license (http://creativecommons.org/licenses/by/4.0/). 